\title{
Present Situation and Countermeasures of English Translation Teaching in University \\ Jianyong Chen ${ }^{1, a^{*}}$ and Ping Yang ${ }^{2, b}$ \\ ${ }^{1}$ Feixian Campus, Linyi University, China \\ ${ }^{2}$ Xiguan Primary School of Feixian, Shandong province, China \\ afxchenjianyong@163.com,byangping-s@163.com
}

Keywords: College English; Translation teaching; Status; Countermeasure

\begin{abstract}
At present, the translation teaching of university has the problem of the lack of translation method, the lack of students 'pragmatic culture knowledge, the obsolete teaching content, and the single teaching method. Therefore, teachers should optimize the integration of translation teaching resources, highlight the method guidance, update the content in a timely manner, strengthen the cultural knowledge learning in English countries and enrich the teaching methods of English translation so as to improve the level of English translation teaching in universities. Translation teaching is an organic part of college English teaching. The level of students 'translation ability reflects the level of students' comprehensive English quality, and also directly affects the college students 'English communication ability. At present, translation teaching has not received enough attention from English teachers, and college students 'translation ability has declined. Therefore, it is urgent for teachers to take effective measures to improve the effectiveness of college English translation teaching.
\end{abstract}

\section{Current Situation of English Translation Teaching in Universities}

Lack of Translation Methods. At present, there is almost no basic theory on translation guidance in college English textbooks. Students generally lack translation methods and skills. Translation has not yet formed ideas, but only stacks of words and phrases. The lack of translation methods and skills is not conducive to the cultivation of students 'English sense.

Lack of knowledge of pragmatic culture. English, as a language, embodies the culture of the English pragmatic area, including people's living habits, pragmatic habits, social customs, etc.. It also embodies customs and history of the regions that use English.In English translation, some cultural knowledge is often involved. However, in translation teaching, teachers do not have high or lack requirements for students 'pragmatic culture. Students have not accumulated enough pragmatic culture, resulting in many mistakes in the translation process.

The Teaching Content of Translation is Outdated. At present, the teaching content of college English translation is relatively old and can not be updated in time, which leads to the lack of practical translation teaching, which also makes students recognize there is no need for translation learning, and there is not enough emphasis on translation learning in ideological understanding. so it is difficult to stimulate students 'interest in learning.

The Teaching Method of Translation is Single. The teaching method of translation has a direct impact on students 'interest in translation learning. The single teaching method of translation is difficult to stimulate students 'initiative in translation learning. So, there is an urgent need for teacher to change teaching thoughts and concepts, and to constantly change the teaching methods of translation. Teacher should combine translation teaching with teaching such as listening, speaking, reading, and writing to create vivid pragmatic situations for students and stimulate students 'enthusiasm for translation.

Not Paying Attention to English Translation Teaching. Due to the low proportion of English translation in examinations, it is not taken seriously in teaching. From the current college English teaching practice, there is a common "exam-oriented" thinking in student English learning. Students 
also perform English translation only to complete homework and to cope with exams. According to the author's teaching practice over the years, although the students 'English level has improved year by year, it is mainly due to the improvement of their listening and reading abilities. This is due to long-term exam-oriented education. Under exam-oriented education, emphasis is placed on listening and reading and neglect English translation.

Lack of Suitable Translation Materials. Many translation teaching materials are old and rigid, and they tend to be translated into English and Chinese in literature. They also have a single teaching form and lack interest. This will not only limit students 'imagination and thinking ability, reduce students' interest in learning, and make them be tired of translation. At the same time, it will be out of touch with the actual needs of today's society. In many institutions, English translation only appears on elective courses, and there is no special translation material for non-English majors and practical translation materials. Translation theory can not be well applied in teaching, and it lacks the learning of translation methods and the mastery of translation skills. Therefore, teaching and practice are disjointed and can not achieve the desired teaching results.

\section{The Way to Improve the Teaching of English Translation in Universities}

The purpose of English translation teaching is to make students better use English, better master English tools, and improve the efficiency and means of information acquisition and output. In the process of translation, it is mainly to understand and express the information expressed by the language in writing or orally, to achieve the acquisition and output of information, and finally to improve the ability of English communication and translation.

Optimizing and Integrating Translation and Teaching Resources. Teaching resources is an effective carrier of teaching and the promotion of translation teaching is closely related the optimal selection of sources . Based on the lack of methods and techniques in translation teaching resources, it is necessary for teachers to optimize and integrate translation teaching resources. First of all, the reasonable choice of English translation materials in accordance with the school situation. Each school should select widely applicable and practical teaching materials according to the training goal of the school personnel and the actual situation of English teaching, especially the translation teaching, and highlight the methods and techniques of translating and learning for students. Secondly, we develop translation teaching resources on the basis of the original teaching materials. Any kind of teaching material has limitations and can not be comprehensive. According to the existing teaching materials, teachers can develop supporting teaching resources and highlight the translation guidance for students. At the same time, considering the content renewal of auxiliary teaching resources, the resources that are close to the times and close to the students 'lives are selected as far as possible. The content must involve many fields, so that students can feel the times and practicality of translation learning, and thus stimulate students' enthusiasm for translation learning.

Strengthening the Learning of Cultural Knowledge in English-speaking Countries. College English translation learning involves the cultural knowledge of English countries, which directly affects students 'understanding of translated texts and their pragmatic habits. Therefore, when teaching translation, English teachers should base their teaching content on the culture of English-speaking countries involved to strengthen the teaching of cultural knowledge and guide students to understand English pragmatics culture in multiple directions. for example, the lifestyle, geography, history, customs, and thinking habits of people in English language areas. At the same time, teachers should guide students to compare Chinese and English culture, especially the thinking habits, customs, and pragmatic habits of people in two language regions. Understanding the commonalities of Chinese and English languages helps students to use their mother tongue learning experience to improve the efficiency of translation learning. In addition, we should focus on understanding and mastering the differences between Chinese and English languages to help students get rid of the influence of their mother tongue on their English translation learning. Finally, some reading tasks should be properly assigned, such as guiding students to read English newspapers and magazines, film and television works, etc.. This will not only help students 
improve their English translation skills, but also help students improve their intercultural language communication skills.

To Continuously Enrich the Teaching Methods of English Translation. In teaching methods, teachers should get rid of the mode of separation translation theory with practice, combine translation theory with practice, help students use translation theory guide pragmatic practice; $\mathrm{Be}$ good at creating vivid pragmatic situations and inspiring students ' interest, strengthen the awareness of translation learning; Be good at using multimedia to aid teaching, for example, to enhance the translation ability of students by watching video in English; We should fully play the role of college English clubs and stimulate students 'initiative in translating and learning in community practice activities. For example, through the adaptation of Chinese and English drama, in exchange for a thinking to cultivate students 'translation skills; We should be good at using comparative teaching, for example, carrying out comparative analysis of Chinese and English expressions, and strengthening students 'English translation ability in comparison.

Pay Attention to English Translation Teaching and Strengthen Translation Training. Translation is a practical skill that must be mastered through continuous training and practice. Therefore, students can experience different practice of translation, teachers can conduct various kinds of translation training in teaching, enable students to master various stylistic translation methods and techniques in practical applications, such as contract, manual, new technology, thesis, etc..,let students be familiar with the translation skills, improve the level of translation. Students should actively understand the content to be translated, understand the translation principles of the same text, be familiar with various types of translation skills, and master corresponding translation methods and strategies, so as to improve students 'translation skills and achieve targeted goals, complete high quality and high standard of translation, truly achieve accurate understanding and expression of information, achieve English and Chinese language and cultural exchanges.

Improving the Professional Competence of Teachers. Under the current education system, due to the influence of the overall focus of teaching, most college English teachers have significantly reduced their quality in their own translation skills, and put more experience and time into theoretical research such as knowledge teaching of basic English theory. They neglect of translation teaching. However, the direct contact of the students is with the teachers. In other words, the translation quality of the English teachers has a direct impact on the improvement of the students 'translation ability. Therefore, in order to improve the teaching level of English translation in college and the translation level of students, we should strengthen the professional training or continuing education of teachers, such as strengthening the training of teachers in translation history, interpretation skills, Eastern and Western translation theory and translation skills. In addition, teachers should establish the belief of lifelong learning, constantly carry on the practice innovation, promote the healthy development of translation teaching.

Organic Combination of Translation Theory Teaching and Practice Teaching. To a certain extent, the improvement of the student's translation ability requires a lot of practice, on the other hand, it alse requires corresponding theoretical guidance. For example, in a non-English major classroom teaching, in order to improve students 'translation ability, teachers should pay attention to teaching Students 'basic learning methods and theoretical knowledge, enhance students' understanding of translation theory, enhance the effect of student practice translation. In actual translation courses teaching, teachers should pay attention to the comparative teaching of Chinese and foreign translation theories in order to let students understand and master translation principles and techniques. Specifically, in combination theoretical teaching with practical teaching, one is that teachers can analyze a large number of examples to improve the understanding and mastery of the theoretical knowledge of students; The second is to allow students to practice on the spot in the classroom; Third, it can be arranged with targeted after-school exercises to improve the ability of flexible use of student translation theory, and then improve the level of translation.

Strengthening Students 'Extra-curricular Translation Practice Activities. Translation is a very practical subject. To improve students 'translation ability, the practice of extra-curricular translation is indispensable. Students can set up various forms of translation practice activities under 
the guidance of teachers. Through the essay translation competition, English-Chinese translation competition, translation knowledge competition and other activities to enhance students 'interest in translation; Practical translation materials such as travel text, summaries, instructions, etc. are selected to allow students to practice in groups to cultivate students 'practical translation skills. Relying on the Internet, set up an interactive platform for translation networks, train students in translation software, database knowledge, translation tools, etc., and make full use of network resources to improve the efficiency and quality of translation; A translation workshop is set up. In the early stage, students can practice from the designated tasks under the guidance of the teacher, send out translation tasks, divide the work and cooperate within the group, complete translation tasks, first proofreading and second proofreading, and the teacher emphasizes the importance of proofreading to the students. Then it is typesetting and delivery. Finally, the teacher points out the problems that students have in practice. After three rounds of practice, the college or teacher can lead the company or translation company to cooperate with the students. The teacher acts as a mentor, so that the students can undertake translation tasks in the real translation environment and improve their translation ability.

\section{Conclusion}

English translation is an important skill. It is a systematic project to develop students 'English translation ability. In teaching, teachers need to explore and study in conjunction with their own teaching practices, improve the teaching level of English translation courses, and create an interactive environment. Students are encouraged to explore and think actively to improve the teaching level of English translation courses.

\section{References}

[1] Lilimin. Cross-cultural awareness training and translation teaching[ $\mathrm{J}]$.. Overseas English, 2013(11):103 -104.

[2] Liulonggen, Hukaibao, Wusijing.. University English Translation Tutorial(third edition)[ M] .. People's University of China Press, 2012.

[3] Wangguilian. Cultural differences and accuracy of translation[ J] .. Shanghai Science and Technology Translation, 2004.

[4] Liuzhongde. Western Translation Research[ M] .. Beijing: China Foreign Translation and Publication Corporation,2003. 